\title{
Developmental enamel defects and their impact on child oral health-related quality of life
}

\section{Fabiana Vargas-Ferreira ${ }^{(a)}$ Thiago Machado Ardenghi(b)}

(a) Department of Community Medicine, School of Epidemiology, Universidade Federal de Pelotas, RS, Brazil.

(b) Department of Stomatology, School of Dentistry, Universidade Federal de Santa Maria, RS, Brazil.
Declaration of Interests: The authors certify that they have no commercial or associative interest that represents a conflict of interest in connection with the manuscript.

\section{Corresponding author:}

Fabiana Vargas-Ferreira

E-mail: fabivfer@yahoo.com.br

Received for publication on Jun 02,2011 Accepted for publication on Sep 30, 2011

\begin{abstract}
This cross-sectional study assessed the impact of Developmental Enamel Defects (DED) on Child Oral Health-Related Quality of Life (COHRQoL). A sample of 944 11- to 14-year-old Brazilian schoolchildren was examined for the prevalence and severity of DED. The children completed the Child Perceptions Questionnaire $\left(\mathrm{CPQ}_{11-14}\right)$, and socioeconomic status was also collected using a questionnaire. Poisson regression models were used to assess the association between DED and overall and domain-specific $\mathrm{CPQ}_{11-14}$ scores. The prevalence of DED was $19.7 \%$. In general, children with DED did not indicate any decrease in self-perception. However, this condition was associated with an impact on the functional limitation domain. The presence of DED may cause negative impacts on a child's perception of oral health and on their daily performance.
\end{abstract}

Descriptors: Tooth Abnormalities; Dentition, Permanent; Dental Enamel Hypoplasia; Quality of Life.

\section{Introduction}

Developmental enamel defects (DED) have been defined as disturbances in hard tissue matrices and their mineralization that arise during odontogenesis. ${ }^{1}$ According to their clinical appearances, DED have been classified as demarcated opacity, diffuse opacity or hypoplasia. ${ }^{1}$ Enamel opacity is a qualitative defect involving an alteration in the translucency of enamel and may appear white, yellow or brown in color. Enamel hypoplasia is a quantitative defect associated with a reduced enamel thickness. $^{2}$

Data on the prevalence of developmental enamel defects of the permanent dentition have been published; the results range from $21 \%$ to nearly $100 \% .^{2-5}$ The presence of DED has been traditionally measured by recording the presence of enamel defects. However, such normative indicators, when employed alone, do not document the full impact of DED on the oral health of a child. ${ }^{6}$ Over the last two decades, increasing attention has been paid to this impact by assessing Child Oral HealthRelated Quality of Life (COHRQoL) by using oral-health surveys and clinical trials. ${ }^{7-8}$

DED may have a significant esthetic impact on the maxillary incisors. ${ }^{4}$ However, no study has yet addressed the impact of this condition on COHRQoL. It is important to understand the true impact of dental 
abnormalities to plan public health policies for the prioritization of care and to evaluate the outcomes from treatment strategies. ${ }^{6}$ This is the first study to evaluate the impact of DED on 11- to 14-year-old Brazilian schoolchildren, and the results may contribute to discussions about whether DED is a public health problem. We believe that DED may cause negative consequences on quality of life.

\section{Methodology}

A cross-sectional study was performed, which used data collected from a multistage random sample of 11- to 14-year-old schoolchildren from Santa Maria, a city in southern Brazil. The city has 263,403 inhabitants, ${ }^{9}$ with nearly $85 \%$ of the population of 12-year-old children enrolled in public schools and residing in the city. The main economic activities are construction, services sector and trade. ${ }^{9}$ To assess the prevalence of DED and the impact of this condition on COHRQoL, we adopted the following sample calculation parameters: a standard error of $5 \%$, a confidence interval level of $95 \%$, a power of $80 \%$ and an expected prevalence of $29.6 \% .{ }^{5}$ In addition, a design effect of 1.4 was applied, and up to $20 \%$ nonresponse was allowed. To achieve a ratio of unexposed to exposed individuals of $3: 1$ and a prevalence ratio of at least $1.6,{ }^{10}$ the minimum required sample size was estimated to be 510 children. A two-stage random sampling procedure was used to select the study sample. The firststage units were all public schools in Santa Maria, Brazil. A total of 20 schools were randomly selected. ${ }^{11}$ The second-stage units were the children enrolled in each selected school, and a random sample of children was selected from a list encompassing all students enrolled in the 20 schools. Only those subjects who were intellectually and physically capable of responding to the questionnaire were included in this study. ${ }^{7}$

The children were clinically examined in their schools by two examiners. This examination was done under natural light in a sitting position using individual CPI probes (ball point), sterilized mouth mirrors and gloves. Sterile gauze pads were used to clean and dry the tooth surfaces. The calibration process lasted $30 \mathrm{~h}$ and included theoretical activi- ties with a discussion on the diagnostic criteria of DED. Moreover, a range of different types of DED based on the diagnosis of photographic images was used in the standardization exercise. ${ }^{1,4}$ The examiners were also trained in the assessment of dental caries, ${ }^{11}$ dental trauma ${ }^{12}$ and tooth erosion, ${ }^{13}$ and these diagnoses were included in the clinical exams carried out for almost all clinical dental conditions except for DED and tooth erosion. A total of 15 children were examined twice by each examiner with an interval of two weeks between each examination. A benchmark dental examiner conducted the complete examiner training process. ${ }^{14}$

We excluded children from this study who had fractured teeth, extensive restorations, or were wearing orthodontic appliances, and we add this information in the paragraph.

The Modified Developmental Enamel Defects inde ${ }^{1}$ was used to diagnose and classify changes in the enamel of the permanent teeth (Figure 1). The buccal surfaces of the following teeth were examined: 11 to 14,21 to 24,36 and 46. Each dental examination followed the international criteria standardized by the World Health Organization for oral health surveys. We recorded the prevalence of dental caries using the DMFT index; ${ }^{11}$ tooth erosion $^{13}$ and dental trauma ${ }^{12}$ were identified as possible confounders. Socioeconomic characteristics were collected through a questionnaire that was completed by the parents of each child. ${ }^{8}$ CORHQoL

Figure 1 - Modified DED index for use in screening surveys (FDI).

\begin{tabular}{l|c}
\hline \multicolumn{1}{c|}{ Types of defects } & Code \\
\hline Normal & 0 \\
\hline Demarcated opacity & 1 \\
\hline Diffuse opacity & 2 \\
\hline Hypoplasia & 3 \\
\hline Other defects & 4 \\
\hline \multicolumn{1}{c}{ Combinations } & Code \\
\hline Demarcated and diffuse & 5 \\
\hline Demarcated and hypoplasia & 6 \\
\hline Diffuse and hypoplasia & 7 \\
\hline All three defects & 8 \\
\hline
\end{tabular}


was measured by using a Brazilian version of the Child Perceptions Questionnaire $\left(\mathrm{CPQ}_{11-14}\right),{ }^{11}$ which addresses the frequency of events occurring during the previous three months. The questionnaire is composed of 37 items distributed among 4 domains:

- oral symptoms (6 questions),

- functional limitations (10 questions),

- emotional well-being (9 questions) and

- social well-being (12 questions).

A 5-point Likert scale is used with the following options:

- 'never' = 0,

- 'once/twice' = 1 ,

- 'sometimes' = 2,

- 'often' $=3$, and

- 'every day/almost every day' $=4$.

The $\mathrm{CPQ}_{11-14}$ scores for each domain are computed by adding all of the item scores under that domain. The total score can vary from 0 to 148 , with a higher score denoting a greater impact on CORHQoL. ${ }^{8}$

Data analyses were performed using Stata 9.0 software (Stata Corporation, College Station, USA). The unadjusted analysis provided summary statistics assessing the association between the outcome and predictor variables. In this study, the outcome was considered a count variable and a parametric assessment of scores associated with answers was performed, as originally proposed in the questionnaire. ${ }^{8}$ Multivariate Poisson regression models, taking into account the cluster sample, were fitted to assess the covariates for the overall and domainspecific $\mathrm{CPQ}_{11-14}$ scores. This strategy allowed the estimation of rate ratios among comparison groups as well as their respective $95 \%$ confidence intervals. A forward stepwise procedure was used to include or exclude explanatory variables in the fitting of the models. Explanatory variables presenting a $P$-value $\leq 0.20$ in the unadjusted analyses were included in the fitting of the models. Explanatory variables were selected for the final models only if they had a $P$-value $\leq 0.05$ after adjustment. DED were entered and retained in the final models regardless of their
$P$-values.

This study was approved by the Human Research Ethics Committee of the Federal University of Santa Maria, and informed consent was obtained from each student prior to beginning the data collection.

\section{Results}

A total of 944 children, $42.5 \%$ boys and $57.5 \%$ girls, were enrolled in this study. The final sample size was larger than the minimum size necessary to satisfy the selected requirements $(\mathrm{N}=510)$ because the survey included other outcomes that required large samples. The response rate was $94 \%$ for all children invited to participate. Reasons for nonparticipation were mainly the lack of parental consent and absence on the day of the exam. For DED, interexaminer and intraexaminer kappa values ranged from 0.62 to 0.80 and from 0.70 to 0.82 , respectively.

Children were predominately white $(79.4 \%)$ and $11-12$ years of age $(67.5 \%)$, with half of them living with a household income equal to or greater than twice the Brazilian Minimum Wage (BMW). The BMW corresponded to nearly 280 US dollars per month at the time of the data-gathering period. The prevalences of dental caries, dental trauma and tooth erosion were $35.3,13.1$ and $7.2 \%$, respectively (Table 1).

Of the 944 children examined, 186 (19.7\%) had at least one enamel defect recorded (Table 1). The frequencies of enamel defects found in all examined teeth showed that dental enamel hypoplasia was the dominant type, being present in almost $41 \%$ of teeth affected by DED (Table 2).

DED was not associated with the mean $\mathrm{CPQ}_{11-14}$ domain and total scores (Table 3). Children with DED did not have higher means of $\mathrm{CPQ}_{11-14}$ domain and total scores when compared with their counterparts. In the multivariate analysis, the same patterns were seen, even after controlling for other possible confounders (Table 4). The prevalence of impact (often - fairly often) showed that children with DED reported a higher impact on the functional limitation domain (RP 1.21; 95\% CI 1.02; 1.48) (Table 4). 
Table 1 - Clinical, demographic and socioeconomic characteristics of the sample $(\mathrm{N}=944)$. Santa Maria. Brazil. 2008.

\begin{tabular}{|c|c|c|}
\hline Variables & $\mathrm{N}^{*}$ & $(\%)$ \\
\hline Sex & 943 & \\
\hline Male & 401 & 42.5 \\
\hline Female & 542 & 57.5 \\
\hline Race & 942 & \\
\hline White & 748 & 79.4 \\
\hline Non-White & 194 & 20.6 \\
\hline Age (years) & 944 & \\
\hline $11-12$ & 637 & 67.5 \\
\hline $13-14$ & 307 & 32.5 \\
\hline Household Income & 855 & \\
\hline$\geq 2 \mathrm{BMW}$ & 455 & 53.2 \\
\hline$<2 \mathrm{BMW}$ & 400 & 46.8 \\
\hline Mother's schooling & 937 & \\
\hline$\geq 8$ years & 533 & 56.9 \\
\hline$<8$ years & 404 & 43.1 \\
\hline Father's schooling & 921 & \\
\hline$\geq 8$ years & 515 & 56.0 \\
\hline$<8$ years & 406 & 44.0 \\
\hline Mother's occupation & 944 & \\
\hline Employed & 839 & 89.0 \\
\hline Unemployed & 105 & 11.0 \\
\hline Father's occupation & 944 & \\
\hline Employed & 416 & 44.0 \\
\hline Unemployed & 528 & 56.0 \\
\hline Tooth Erosion & 944 & \\
\hline Without & 903 & 92.8 \\
\hline With & 68 & 7.2 \\
\hline Enamel defects & 944 & \\
\hline Without & 758 & 80.3 \\
\hline With & 186 & 19.7 \\
\hline Dental caries & 944 & \\
\hline $\mathrm{DMF}=0$ & 611 & 64.7 \\
\hline $\mathrm{DMF}>0$ & 333 & 35.3 \\
\hline
\end{tabular}

* values lower than 944 due to missing data; BMW = Brazilian Minimum Wage $=280$ US dollars; DMF = decayed, missed, filled teeth.

\section{Discussion}

This is the first study that assessed the impact of DED using $\mathrm{CPQ}_{11-14}$. We found that DED did not
Table 2 - Prevalence of enamel defects in Brazilian schoolchildren ( $\mathrm{N}=$ 944), Santa Maria. 2008.

\begin{tabular}{l|c}
\hline \multicolumn{1}{c|}{ Types of defects (by tooth) } & Prevalence (\%) \\
\hline Demarcated opacity & 1.17 \\
\hline Diffuse opacity & 0.44 \\
\hline Hypoplasia & 40.78 \\
\hline \multicolumn{1}{c}{ Combinations } & 0.11 \\
\hline Demarcated and diffuse & \\
\hline Demarcated and hypoplasia & 0 \\
\hline Diffuse and hypoplasia & 2.76 \\
\hline All three defects & 0.22 \\
\hline
\end{tabular}

have an impact on COHRQoL, except for on the functional limitation domain.

The prevalence of DED found in this study was lower than the majority of findings reported by several other authors in different countries..$^{2-5,15,16}$ In Brazil, a population-based study showed a prevalence of $29.7 \%$ without the occurrence of dental fluorosis; ${ }^{5}$ this result is similar to results found in Malaysia ${ }^{17}$ and Tonga. ${ }^{18}$ However, a much higher prevalence of DED that could reach $100 \%$ was reported among children from $\mathrm{China}^{2}$ as well as New Zealand. ${ }^{4}$ The variation in prevalence is due to the types of defects studied; different classifications of indices or modifying established indices; different field settings and technical examination procedures, such as lighting or whether the teeth were dried or not; and factors in the population, such as genetic, racial, ethnic and socioeconomic status. ${ }^{4,5}$

Among the three types of defects examined, hypoplasia was the most commonly found in examined teeth $(40.7 \%)$. Similar findings were reported from a study in Iran, ${ }^{15}$ in which these defects were more prevalent $(32.7 \%)$. In other investigations, the prevalence of hypoplasia ranged between 0.8 and $82.8 \% .^{5,16-19}$ Possible explanations for this discrepancy are attributed to the differences in geographical region, mainly in relation to the amount of fluoride in the drinking water of each target group. ${ }^{15}$ Demarcated opacities were the most prevalent enamel defects in several studies, ${ }^{2,5,20}$ and diffuse opacities were the most prevalent in others. ${ }^{16,18}$ 


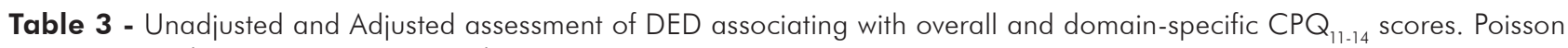
regression analysis. Santa Maria. Brazil. 2008.

\begin{tabular}{|c|c|c|c|c|c|c|}
\hline & $\begin{array}{c}\text { With DED } \\
\text { Mean ( } \pm \text { SD) }\end{array}$ & $\begin{array}{l}\text { Without DED } \\
\text { Mean ( } \pm \text { SD) }\end{array}$ & $\begin{array}{l}\text { RR Unadj. } \\
(95 \% \mathrm{Cl})\end{array}$ & $\mathrm{p}$ & $\begin{array}{l}\text { RR*Adjust } \\
\text { (95\%Cl) }\end{array}$ & $p$ \\
\hline$C P Q_{11-14}$ (overall scale) & 18.20 (13.33) & $18.70(14.32)$ & $0.97(0.86 ; 1.09)$ & 0.65 & $0.96(0.86 ; 1.08)$ & 0.55 \\
\hline \multicolumn{7}{|l|}{ Domains } \\
\hline Oral Symptoms & $5.43 \quad(3.50)$ & $6.07 \quad(3.55)$ & $0.89(0.81 ; 1.00)$ & 0.06 & $0.90(0.81 ; 1.00)$ & 0.06 \\
\hline Functional Limitation & $4.88 \quad(4.20)$ & $4.36 \quad(4.28)$ & $1.12(0.97 ; 1.29)$ & 0.12 & $1.11(0.96 ; 1.28)$ & 0.15 \\
\hline Emotional Well-Being & $5.06 \quad(5.97)$ & $5.15 \quad(6.35)$ & $0.98(0.81 ; 1.19)$ & 0.86 & $0.97(0.81 ; 1.16)$ & 0.73 \\
\hline Social Well-Being & $2.80 \quad(3.30)$ & $3.11 \quad(4.16)$ & $0.90(0.74 ; 1.09)$ & 0.29 & $0.91(0.75 ; 1.10)$ & 0.32 \\
\hline
\end{tabular}

*Adjusted by age, sex, race, parents' education level, parent's occupation, household income, tooth erosion, dental caries and dental trauma; RR - rate ratio.

Table 4 - Association between DED and the prevalence of impacts ("very often"/"fairly often") of overall and domain-specific $C P Q_{11-14}$ scores. Poisson regression analysis. Santa Maria. Brazil. 2008.

\begin{tabular}{|c|c|c|c|c|c|c|}
\hline & $\begin{array}{c}\text { With DED } \\
N^{*}(\%)\end{array}$ & $\begin{array}{c}\text { Without DED } \\
N^{*}(\%)\end{array}$ & $\begin{array}{l}\text { RP Unadj. } \\
(95 \% \mathrm{Cl})\end{array}$ & $\mathrm{p}$ & $\begin{array}{c}\text { RP**Adjust. } \\
\text { (95\%Cl) }\end{array}$ & $p$ \\
\hline$C P Q_{11-14}$ (overall scale) & 108 (20.93) & $408(79.07)$ & $1.08(0.94 ; 1.24)$ & 0.28 & $1.07(0.93 ; 1.23)$ & 0.32 \\
\hline \multicolumn{7}{|l|}{ Domains } \\
\hline Oral Symptoms & $45(17.37)$ & $214(82.63)$ & $0.86(0.65 ; 1.13)$ & 0.27 & $0.84(0.64 ; 1.11)$ & 0.21 \\
\hline Functional Limitation & 77 (23.19) & $255(76.81)$ & $1.23(1.01 ; 1.50)$ & 0.04 & $1.21(1.02 ; 1.48)$ & 0.05 \\
\hline Emotional Well-Being & 38 (19.79) & $154(80.21)$ & $1.00(0.73 ; 1.38)$ & 0.97 & $0.96(0.70 ; 1.31)$ & 0.78 \\
\hline Social Well-Being & $23(19.33)$ & $96(80.67)$ & $0.98(0.64 ; 1.49)$ & 0.91 & $0.98(0.64 ; 1.50)$ & 0.94 \\
\hline
\end{tabular}

* Number and percentage reporting items "very often" and "fairly often"; * Adjusted by age, sex, race, parents' education level, parent's occupation, household income, tooth erosion, dental caries and dental trauma.

In relation to the diagnosis of $\mathrm{DED}$, enamel hypoplasia and demarcated opacities are easily detected because of their characteristic clinical appearances while diffuse opacities represent more nonspecific changes and do not present a very precise border against the adjacent normal enamel. ${ }^{21}$

To analyze the impact of DED on quality of life, we assessed enamel defects in two forms: the prevalence of children with DED and the prevalence of teeth with enamel defects. In relation to the severity, we considered dental enamel hypoplasia to be the most severe because this type of defect may cause tooth sensitivity or be more susceptible to dental cavities. ${ }^{16,22}$

Although several epidemiologic surveys have collected data regarding the prevalence and severity of DED in children and adolescents, ${ }^{2-5}$ the implications of DED on COHRQoL is yet unknown. This oral condition may be associated with altered esthetics ${ }^{4}$ that could affect COHRQoL.

The presence of DED did not have a significant impact on the $\mathrm{CPQ}_{11-14}$ domain and total scores, except for on the functional limitation domain. In general, children with DED (mainly opacities) rarely showed symptoms or any discomfort at this low level of severity. It is possible that, taken together, the low prevalence of DED found in children when compared with the results of other studies reported in this investigation could have influenced such results. Therefore, the data may have been underestimated, and further studies on a different age-group with a higher level of prevalence of DED are needed to confirm these findings.

However, even at a low level of severity (presence of opacities), the presence of DED may influence a child's dental appearance. ${ }^{23-24}$ There is a potential for hypoplasia to cause a negative impact because this type of enamel defect is more severe. 
In this study, hypoplasia was more prevalent among the children assessed, and this result may explain the association between DED and impacts on the functional limitation domain (Table 4), which is in agreement with the literature..$^{16,22}$

Our data must be considered with caution because our findings are limited by the cross-sectional nature of the data. Further investigations using different study designs (longitudinal) and different criteria to diagnose DED are needed to confirm these findings. Moreover, some reported results could be due to other oral conditions. To minimize this bias, we also examined the children for other potential confounding variables, such as untreated dental caries.

Despite its limitations, this study offers relevant perspective for public health and the scientific community. The results shown here provide a broad assessment of DED encompassing both subjective and normative measurements of the disease. They may

\section{References}

1. Fédération Dentaire Internationale Working Group: A review of developmental defects of the enamel dental index (DDE Index). Commission on Oral Health, Research \& Epidemiology. Int Dent J 1992; 42(6): 411-26.

2. King NM. Developmental defects of enamel in chinese girls and boys in Hong Kong. Adv Dent Res. 1989 Sep;3(2):120-5.

3. Ekanayke L, Van der Hoek W. Dental caries and developmental defects of enamel in relation to fluoride levels in drinking water in Arid area of Sri Lanka. Caries Res. 2002 NovDec;36(6):398-404.

4. Mackay TD, Thomson WM. Enamel defects and dental caries among Southland children. N Z Dent J. 2005 Jun;101(2):3543.

5. Hoffmann RHS, Sousa MLR, Cypriano S. [Prevalence of enamel defects and the relationship to dental caries in deciduous and permanent dentition in Indaiatuba, São Paulo, Brazil]. Cad Saude Publica. 2007 Feb;23(2):435-44. Portuguese.

6. Gherunpong S, Tsakos G, Sheiham A. The prevalence and severity of oral impacts on daily performances in Thai primary school children. Health Qual Life Outcomes. 2004 Oct 12;2;57. doi: 10.1186/1477-7525-2-57

7. Piovesan C, Antunes JLF, Guedes RS, Ardenghi TM. Impact of socioeconomic and clinical factors on child oral healthrelated quality of life (COHRQoL). Qual Life Res. 2010 Nov;19(9):1359-66. be useful for the evaluation of oral health programs and services and the reorientation of health care according to preferential needs. ${ }^{8}$ Moreover, the assessment of the association among the group of affected teeth, the DED type present and the impact on the different domains of quality of life may contribute to a better understanding of the impact of DED on the life of children and adolescents.

\section{Conclusion}

Our results indicated that the presence of DED may cause negative impacts on a child's perception of oral health and on their daily performance.

\section{Acknowledgments}

The authors would like to thank all the children, parents and schools for their cooperation, and the Municipal Education Authorities of Santa Maria, RS, for all the information and authorization related to this study.

8. Vargas-Ferreira F, Piovesan C, Praetzel JR, Mendes FM, Allison P, Ardenghi, TM. Tooth erosion with low severity does not impact child oral health-related quality of life. Caries Res. 2010 Dec;44(6):531-9.

9. Instituto Brasileiro de Geografia e Estatística. Pesquisa Nacional por Amostra de Domicílios: síntese de indicadores - 2003 [internet]. [cited 2011 jul 22]. Available from:http://www. ibge.gov.br/home/estatistica/populacao/trabalhoerendimento/ pnad2003/sintesepnad2003.pdf.

10. Camargo MBJ, Dumith SC, Barros AJD. [Regular use of dental care services by adults: patterns of utilization and types of services]. Cad Saude Publica. 2009 Sep;25(9):1894-906. Portuguese.

11. World Health Organization. Oral health surveys, basic methods. $4^{a}$ ed. Geneva: WHO; 1997.93 p.

12. O'Brien M. Report of dental survey, Office of Population Censuses and Surveys. $2^{\text {nd }}$ ed. London: Her Majesty's Stationery Office; $1994.130 \mathrm{p}$.

13. O'Sullivan EA. A new index for the measurement of erosion in children. Eur J Paediatr Dent. 2000 Jan;1(1):69-74.

14. Vargas-Ferreira F, Praetzel JR, Ardenghi TM. Prevalence of tooth erosion and associated factors in 11-14-yearl old Brazilian children. J Public Health Dent. 2011 Jan;71(1):6-12.

15. Daneshkazemi AR, Davari A. Assessment of DMFT and enamel hypoplasia among junior high school children in Iran. J Contemporary Dent Pract. 2005 Nov;6(4):1-7. 
16. Schluter PJ, Kanagaratnam S, Durward CS, Mahood R. Prevalence of enamel defects and dental caries among 9-year-old Auckland children. N Z Dent J. 2008 Dec; 104(4):145-52.

17. Nik-Hussein NN, Majid ZA, Mutalib KA, Abdullah F, Abang A, Wan MN. Prevalence of developmental defects of enamel among 16-year-old children in Malaysia. Annal Dent Univ Malaya. 1999 Jun;6(4):11-6.

18. Hoffman MP, Cutress TW, Tomiki S. Prevalence of developmental defects of enamel in children in the Kingdom of Tonga. N Z Dent J. 1988 Jan;84(375):7-10.

19. Downer MC, Blinkhorn AS, Holt RD, Wight C, Altwood D. Dental caries experience and defects of dental enamel among 12-year-old children in North London, Edinburgh, Glasgow and Dublin. Community Dent Oral Epidemiol. 1994 Oct;22(5):283-5.

20. Dummer PMH, Kingdom A, Kingdom R. Prevalence of enamel developmental defects in a group of 11- and 12-year-old chil- dren in South Wales. Community Dent Oral Epidemiol. 1986 Apr;14(2):119-22.

21. Lunardelli SE, Peres MA. Prevalence and distribution of developmental enamel defects in the primary dentition of pre-school children. Braz Oral Res. 2005 Apr-Jun;19(2):144-9.

22. Goursand D, Paiva SM, Zarzar PM, Ramos-Jorge ML, Pordeus IA, Allison PJ. Cross-cultural adaptation of the Child Perceptions Questionnaire 11-14 (CPQ ${ }_{11-14}$ ) for the Brazilian Portuguese language. Health Qual Life Outcomes. 2008 Jan14;6:2. Dói: 10.1186/1477-7525-6-2.

23. Sujak SL, Kadir RA, Dom TNM. Esthetic perception and psychosocial impact of developmental enamel defects among Malaysian adolescents. J Oral Sc. 2004 Dec;46(4):221-6.

24. Marshaman Z, Gibson B, Robinson PG. The impact of developmental defects of enamel on young people in the UK. Community Dent Oral Epidemiol. 2009 Feb;37(1):45-57. 